\title{
Dissolution Media Simulating Fasted and Fed States
}

\author{
Margareth Marques \\ United States Pharmacopeia \\ Rockville, $M D$
}

W hen dissolution testing is used to forecast the in vivo performance of a drug, it is critical that the in vitro test mimic the conditions in vivo as closely as possible. A team of researchers, led by Dr. Jennifer Dressman of the J.W. Goethe University, Germany, has developed biorelevant gastrointestinal media that simulate the fasted and fed states. These media have been used to examine the solubility and dissolution characteristics of several classes of drugs including poorly soluble weak bases and lipophilic drugs to assist in predicting in vivo absorption behavior (1).

Biorelevant in vitro dissolution testing is useful for qualitative forecasting of formulation and food effects on the dissolution and availability of orally administered drugs. It has been observed that biorelevant media can provide a more accurate simulation of pharmacokinetic profiles than simulated gastric fluid or simulated intestinal fluid.

The use of biorelevant media can have a great impact on the pharmacokinetic studies performed to optimize dosing conditions and product formulation. In addition, biorelevant dissolution testing could be used to assess bioequivalence of post-approval formulation changes in certain kinds of drugs (2-5).

The formulation and preparation instructions for the biorelevant media developed by Dr. Dressman's group are detailed below.

$\begin{array}{lc}\text { Fasted State Simulated Intestinal Fluid (FaSSIF) } \\ \text { Sodium taurocholate } & 3 \mathrm{mM} \\ \text { Lecithin } & 0.75 \mathrm{mM} \\ \mathrm{NaOH} \text { (pellets) } & 0.174 \mathrm{~g} \\ \mathrm{NaH}_{2} \mathrm{PO}_{4} \cdot \mathrm{H}_{2} \mathrm{O} & 1.977 \mathrm{~g} \\ \mathrm{NaCl} & 3.093 \mathrm{~g} \\ \text { Purified water qs. } & 500 \mathrm{~mL} \\ \text { Media has a pH of } 6.50 \text { and an osmolality of about } 270 \mathrm{mOsmol} / \mathrm{kg} .\end{array}$

\section{Preparation of blank FaSSIF}

Dissolve $1.74 \mathrm{~g}$ of $\mathrm{NaOH}$ (pellets), $19.77 \mathrm{~g}$ of $\mathrm{NaH}_{2} \mathrm{PO}_{4} \cdot \mathrm{H}_{2} \mathrm{O}$ or $17.19 \mathrm{~g}$ of anhydrous $\mathrm{NaH}_{2} \mathrm{PO}_{4}$, and 30.93 $\mathrm{g}$ of $\mathrm{NaCl}$ in $5 \mathrm{~L}$ of purified water. Adjust the $\mathrm{pH}$ to exactly 6.5 using $1 \mathrm{~N} \mathrm{NaOH}$ or $1 \mathrm{~N} \mathrm{HCl}$.

\section{Preparation of FaSSIF}

Dissolve $3.3 \mathrm{~g}$ of sodium taurocholate in $500 \mathrm{~mL}$ blank FaSSIF. Add $11.8 \mathrm{~mL}$ of a solution containing $100 \mathrm{mg} / \mathrm{mL}$ lecithin in methylene chloride, forming an emulsion. The methylene chloride is eliminated under vacuum at about $40^{\circ} \mathrm{C}$. Draw a vacuum for fifteen minutes at $250 \mathrm{mbar}$, followed by 15 minutes at 100 mbar. This results in a clear, micellar solution, having no perceptible odor of methylene chloride. After cooling to room temperature, adjust the volume to $2 \mathrm{~L}$ with blank FaSSIF.
For dissolution tests a volume of $500 \mathrm{~mL}$ is recommended.

Fed State Simulated Intestinal Fluid (FeSSIF)

Sodium taurocholate $\quad 15 \mathrm{mM}$

Lecithin $\quad 3.75 \mathrm{mM}$

$\mathrm{NaOH}$ (pellets) $\quad 4.04 \mathrm{~g}$

Glacial Acetic Acid $\quad 8.65 \mathrm{~g}$

$\mathrm{NaCl} \quad 11.874 \mathrm{~g}$

Purified water qs. $\quad 1000 \mathrm{~mL}$

Media has a pH of 5.00 and an osmolality of about $670 \mathrm{mOsmol} / \mathrm{kg}$

Preparation of blank FeSSIF

Dissolve $20.2 \mathrm{~g}$ of $\mathrm{NaOH}$ (pellets), $43.25 \mathrm{~g}$ of glacial acetic acid, and $59.37 \mathrm{~g}$ of $\mathrm{NaCl}$ in $5 \mathrm{~L}$ of purified water. Adjust the $\mathrm{pH}$ to exactly 5.0 using $1 \mathrm{~N} \mathrm{NaOH}$ or $1 \mathrm{~N} \mathrm{HCl}$.

Preparation of FeSSIF

Dissolve $16.5 \mathrm{~g}$ of sodium taurocholate in $500 \mathrm{~mL}$ of blank FeSSIF. Add $59.08 \mathrm{~mL}$ of a solution containing 100 $\mathrm{mg} / \mathrm{mL}$ lecithin in methylene chloride, forming an emulsion. The methylene chloride is eliminated under vacuum at about $40^{\circ} \mathrm{C}$. Draw a vacuum for fifteen minutes at 250 mbar, followed by 15 minutes at 100 mbar. This results in a clear to slightly hazy, micellar solution having no perceptible odor of methylene chloride. After cooling to room temperature, adjust the volume to $2 \mathrm{~L}$ with blank FeSSIF.

The recommended volume for simulating conditions in the upper small intestine after a meal is one liter.

\section{References}

1. Kostwicz, E. S., Brauns, U., Becker, R., Dressman, J. B. Forecasting the oral absorption behavior of poorly soluble weak bases using solubility and dissolution studies in biorelevant media. Pharm. Res., 19(3): 345-349, 2002.

2. Dressman, J. B., Reppas, C. - In vitro-in vivo correlations for lipophilic, poorly water-soluble drugs. B.T. Gattefosse, 93: 91-100, 2000.

3. Nicolaides, E., Symillides, M., Dressman, J. B., Reppas, C. - Biorelevant dissolution testing to predict the plasma profile of lipophilic drugs after oral administration. Pharm. Res., 18(3): 380-388, 2001.

4. Horter, D., Dressman, J. B. - Influence of physicochemical properties on dissolution of drugs in the gastrointestinal tract. Adv. Drug Del. Rev., 46: 75-87, 2001.

5. Lobenberg, R., Kramer, J., Shah, V. P., Amidon, G. L., Dressman, J. B. - Dissolution testing as a prognostic tool for oral drug absorption: Dissolution behavior of glibenclamide. Pharm. Res., 17: 439-444, 2000. 